\title{
Colorectal Carcinoma Metastatic in the Liver
}

National Cancer Institute

\section{Source}

National Cancer Institute. Colorectal Carcinoma Metastatic in the Liver. NCI Thesaurus.

Code C157366.

A carcinoma that originates from the colorectal area and has spread to the liver. 